\title{
Triplex Formation Inhibits HER-2/neu Transcription In Vitro
}

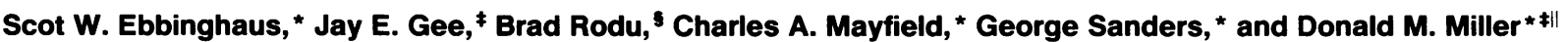

Departments of ${ }^{*}$ Medicine, ${ }^{\ddagger}$ Biochemistry, and Oral Pathology, University of Alabama at Birmingham, and $"$ Birmingham Veterans Affairs Medical Center, Birmingham, Alabama 35294

\begin{abstract}
Triplex-forming oligonucleotides (TFOs) have been shown to bind to target DNA sequences in several human gene promoters such as the c-myc oncogene, the epidermal growth factor receptor, and the dihydrofolate reductase genes. TFOs have been shown to inhibit transcription in vitro and gene expression in cell culture of the c-myc and other genes. The HER-2/neu oncogene, which is overexpressed in breast cancer and other human malignancies, contains a purine-rich sequence in its promoter, which is favorable for purine:purine:pyrimidine (R:R:Y) triplex formation. Although its function in the HER-2/neu promoter is unknown, this purine-rich site is homologous to a protein-binding sequence in the promoter of the epidermal growth factor receptor that is necessary for efficient transcription of this gene. We have shown that this sequence is a site for nuclear protein binding by incubation with a crude nuclear extract. We describe the formation of an interstrand triplex using a purine-rich oligonucleotide antiparallel to this purine-rich target sequence of the HER-2/neu promoter. Triplex formation by the oligonucleotide prevents protein binding to the target site in the HER-2/neu promoter in vitro. We have shown that this oligonucleotide is a potent and specific inhibitor of HER-2 / neu transcription in an in vitro assay. The triplex target site contains a single pyrimidine base that does not conform to the R:R:Y triplex motif. In an attempt to abrogate the potentially destabilizing effects of this pyrimidine base on triplex formation, we have substituted an abasic linker for the pyrimidine residue in the triplex forming oligonucleotide. Triplex formation with the modified oligonucleotide appears to occur with approximately equivalent binding affinity. Triplex formation in the HER-2/neu oncogene promoter prevents transcription in vitro and may represent a future modality for specific inhibition of this gene in vivo. (J. Clin. Invest. 1993. 92:2433-2439.) Key words: footprint • gel shift • sequence DNA • oncogene • gene expression
\end{abstract}

\section{Introduction}

The neu oncogene was originally described in NIH3T3 transfectants from ethylnitrosourea-induced tumors in rats $(1,2)$. The human counterpart, c-erbB- 2 or HER- 2 /neu, encodes a

Address correspondence to Donald M. Miller, M.D., Ph.D., 1824 6th Avenue South, Wallace Tumor Institute, Room 520, Birmingham, AL 35294. The current address for Jay E. Gee is Center for Biotechnology, Baylor College of Medicine, The Woodlands, TX 77380. 1993

Received for publication 15 June 1992 and in revised form 11 May

J. Clin. Invest.

(c) The American Society for Clinical Investigation, Inc.

$0021-9738 / 93 / 11 / 2433 / 07 \quad \$ 2.00$

Volume 92, November 1993, 2433-2439
$185-\mathrm{kD}$ protein that is homologous to the EGF receptor (EGFR $)^{1}(3,4)$. A point mutation changing a single amino acid in the membrane spanning domain leads to deregulation of tyrosine kinase activity and transformation of cells bearing this mutant protein (5-7). A stimulatory ligand for the HER-2/ neu gene product has recently been described ( 8 ). HER-2/neu is amplified and/or overexpressed in $\sim 25 \%$ of human breast cancer and correlates with advanced disease and poor outcome $(9,10)$; however, the point mutation described for in vitro activation of the HER-2/neu oncogene is absent in the amplified HER-2/neu oncogene in human tumor specimens (11).

The HER-2/neu promoter contains typical CCAAT and TATA elements that are separated by a 45-base segment that is $78 \%$ purine on the coding strand (Fig. 1)(12). A portion of this region is homologous to a segment of the EGF-R promoter that binds a transcription factor named TC factor (TCF) for the pyrimidine-rich nature of its recognition sequence (13). This sequence in the EGF-R promoter appears to be necessary for efficient transcription of EGF-R (13), but its function in the HER-2/neu promoter is not known.

Oligonucleotides have now been shown to form interstrand DNA triple helices in a number of naturally occurring purine rich sequences. The promoters of the human c-myc, EGF-R, dihydrofolate reductase (DHFR), and IL-2 receptor (IL-2-R) genes have been successfully targeted for site-specific triplex formation (14-18). In addition, sequences in the HIV long terminal repeat (LTR) (19) and coding sequence (20) are targets for triplex formation. Triplex formation in DNA target sequences can effectively inhibit protein binding and gene expression (21). The transcription factor $\mathrm{Sp} 1$ has binding sites in the DHFR promoter; triplex formation at these sites prevents Spl binding (17). In addition, triplex formation prevents nuclear factor kappa B (NFkB) binding to the $\alpha$-regulatory sequence of the IL-2-R promoter (18). Triplex-forming oligonucleotides (TFOs) have been shown to inhibit in vitro transcription of c-myc and HIV-LTR $(15,19)$. Messenger RNA levels of c-myc have been measured in HeLa cells in culture with and without TFO, and these oligonucleotides apparently inhibit cellular c-myc transcription (22). Cellular IL-2-R transcription is inhibited by a TFO in a chloramphenicol acetyl transferase assay (18), and a TFO has been shown to inhibit HIV transcription and viral proliferation in virally infected cells in culture (19).

Interstrand DNA triplex formation typically occurs at polypurine/polypyrimidine tracts (14-23). An exogenous polypurine oligonucleotide forms the third strand by occupying the major groove of the native duplex and forming Hoogsteen hydrogen bonds with the purine bases of the duplex (23-25). The

1. Abbreviations used in this paper: CMV, cytomegalovirus; DHFR, dihydrofolate reductase; EGF-R, EGF receptor; IL-2-R, IL-2 receptor; LTR, long terminal repeat; TCF, a transcription factor named TF factor; TFOs, triplex-forming oligonucleotides. 


\section{The HER-2/neu Promoter}

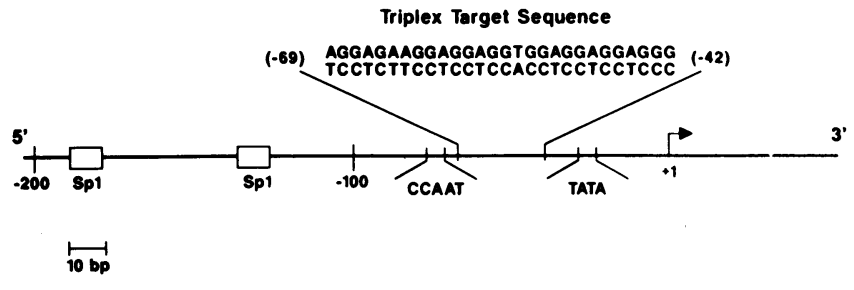

Figure 1. Map of the HER-2/neu promoter showing the triplex target sequence and relative positions of control elements including two Spl binding sites at -192 to -183 and -136 to -127 , the CCAAT box at -76 to -73 , and the TATA box at -28 to -25 relative to the major transcription start site $(+1)$.

base triplets in this purine:purine:pyrimidine (R:R:Y) triplex include G:G:C and A:A:T (third strand bases in bold), and the Hoogsteen bonding makes the triplex sequence specific $(24,25)$.

While purine-rich sequences occur disproportionately in the promoters of eukaryotic genes (23), there are often pyrimidines interspersed in the polypurine tract that make triplex formation less favorable. Nonetheless, triplex formation has been shown in several naturally occurring sequences that are not strictly homopurine:homopyrimidine (14-20). Pyrimidine interruptions of the polypurine tract potentially disrupt the ability of these sequences to form triplex because of the loss of Hoogsteen hydrogen bonds $(25,26)$. It would be desirable to bridge these interruptions in a manner that minimizes steric interactions that could be destabilizing to triplex formation. An abasic molecule that maintains the proper internucleotide spacing (27) would be ideally suited as such a bridge. We have examined the effect of substituting an abasic bridge for a pyrimidine residue in a purine-rich triplex forming oligonucleotide.

We determined the ability of a polypurine oligonucleotide to form an interstrand triplex with the purine-rich segment of the HER-2/neu promoter from -42 to -69 relative to the major transcription start site. This site was shown to bind nuclear protein from a crude nuclear extract, and the effect of triplex formation on nuclear protein binding to the HER-2/ neu promoter and to the target sequence were also examined. The effect of triplex formation on a cell-free in vitro transcription assay was examined. This target sequence contains a single internal pyrimidine (thymidine at -54 ) and 27 purines. We evaluated an oligonucleotide with a single substitution of the thymidine residue by an abasic linker molecule.

\section{Methods}

Oligonucleotide synthesis. Oligonucleotides were synthesized by standard phosphoramidite chemistry on a DNA synthesizer (Cyclone Plus; Millipore Corp., Bedford, MA), purified by reverse phase chromatography (Sep-Pak), and yields were checked by optical density at $260 \mathrm{~nm}$. The integrity of the oligonucleotides was verified by gel electrophoresis. Oligonucleotides were labeled by $\mathrm{T} 4$ polynucleotide kinase reaction with ${ }^{32} \mathrm{P}$-ATP. The linker substituted oligonucleotide was synthesized by dissolving the solid reagent $\left(N\right.$-Fmoc-O ${ }^{1}$-DMT-O ${ }^{3}$-cyanoethoxydiisopropylaminophosphinyl-2-aminobutyryl-1,3-propanediol, Unilink Aminomodifier; Clontech, Palo Alto, CA) in anhydrous acetonitrile and placing it in the auxillary port of the synthesizer. The sequences of oligonucleotides are illustrated in Fig. 2.

Gel mobility shift. Oligonucleotides were incubated together in a buffer consisting of $90 \mathrm{~mm}$ Tris, $90 \mathrm{~mm}$ borate, $10 \mathrm{~mm} \mathrm{MgCl}_{2}$ (final
$\mathrm{pH}=8.0$ ) at $37^{\circ} \mathrm{C}$ for $15 \mathrm{~min}$, then at room temperature for $15 \mathrm{~min}$, then at $4^{\circ} \mathrm{C}$ for $15 \mathrm{~min}$. Glycerol (final concentration 5\%) with bromphenol blue and xylene cyanol was used to load the reaction onto a $20 \%$ native polyacrylamide gel that was run at $80 \mathrm{~V}(8 \mathrm{~V} / \mathrm{cm})$ for $14 \mathrm{~h}$ at $4^{\circ} \mathrm{C}$. Bands were visualized by autoradiography. A HeLa nuclear extract was prepared (28) for use in the protein binding shifts. Oligonucleotides were incubated with a labeled Thal digested fragment of the HER-2/neu promoter or with a labeled synthetic fragment in the buffer used in other gel shifts at room temperature for $30 \mathrm{~min}$. Then 3 $\mu \mathrm{g}$ of poly ( $\mathrm{dIdC}$ ) and $5 \mu \mathrm{l}$ of the extract were added and incubated for $30 \mathrm{~min}$ at room temperature. Glycerol with bromphenol blue and $x y-$ lene cyanol was added, and the reaction was loaded onto a $5 \%$ native polyacrylamide gel and run at $150 \mathrm{~V}$ for $2-3 \mathrm{~h}$ followed by autoradiography.

DNase I footprint. A 267-bp fragment of the HER-2/neu promoter was amplified from HL-60 DNA by PCR and cloned into a plasmid vector (TA1000; Invitrogen, San Diego, CA). The coding strand was labeled by plasmid digestion followed by the Klenow reaction. For the non-coding strand the downstream PCR primer was 5 ' end labeled by $\mathrm{T}_{4}$ kinase reaction; end-labeled DNA was obtained by PCR amplification of the HER-2/neu promoter-plasmid construct. The sequences of the cloned and amplified DNAs were confirmed by Maxam-Gilbert sequencing (29). DNA was incubated with the oligonucleotide in a buffer consisting of $90 \mathrm{~mm}$ Tris- $\mathrm{HCl}, \mathrm{pH} 7.4,10 \mathrm{~mm} \mathrm{MgCl} 2$ as described above. The buffer differed from the one used in gel shift analysis because of improved enzymatic activity of DNase I. $3 \mu \mathrm{g}$ of poly (dI$\mathrm{dC}$ ) was added. The DNA was subjected to a 5-min digestion on ice with 0.1-1 U of DNase I and the reaction stopped by adding formamide with bromphenol blue and xylene cyanol and heating to $95^{\circ} \mathrm{C}$ for $5 \mathrm{~min}$ and then quickly cooling. The samples were loaded onto an $8 \%$ polyacrylamide gel, $8 \mathrm{M}$ in urea, and run at $40 \mathrm{~W}$ for $3 \mathrm{~h}$ followed by autoradiography. The promoter fragment and triplex target sequence are illustrated in Fig. 1.

Calculation of $K_{d}$. The ratio of duplex (D) to triplex (T) was determined by densitometry of autoradiograms and the $K_{\mathrm{d}}$ was calculated by

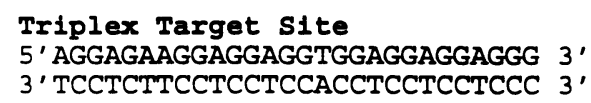

Antiparallel Oligonucleotide

5' GGGAGGAGGAGGTGGAGGAGGAAGAGGA 3'

Parallel oligonucleotide

5' AGGAGAAGGAGGAGGTGGAGGAGGAGGG 3'

Iinker Substituted oligonucleotide

5 ' GGGAGGAGGAGGXGGAGGAGGAAGAGGA 3'

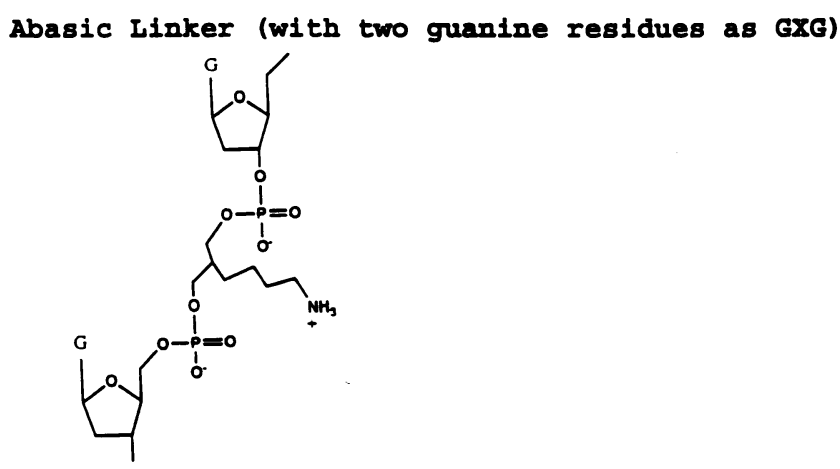

Figure 2. Oligonucleotide sequences and abasic linker molecule (illustrated in a sequence between two guanine residues). 
$\mathrm{D} / \mathrm{T}=K_{\mathrm{d}} \times 1 /[\mathrm{Pu}]$, where $[\mathrm{Pu}]$ is the final concentration of purine oligonucleotide (14).

In vitro transcription assay. The plasmid containing the 267-bp HER-2/neu promoter includes the transcription start site and was used for in vitro transcription. NotI digestion of this plasmid yields a 610 -bp fragment with $368 \mathrm{bp}$ downstream of the transcription start site and will yield an RNA transcript of approximately this size in run-off transcription. The template DNA $(1 \mu \mathrm{g})$ was incubated with varying concentrations of the triplex-forming oligonucleotide or a purine-rich control oligonucleotide in a buffer identical to the one used for gel shift analysis for $1 \mathrm{~h}$ at $37^{\circ} \mathrm{C}$. As another control, a cytomegalovirus promoter template ( $100 \mathrm{ng}$ ) yielding a 363-base transcript (Promega Biotec, Madison, WI) was handled identically to the HER-2/neu template. As discussed in Results below, we found high concentrations of several oligonucleotides to inhibit transcription in this assay system nonspecifically. Therefore, after triplex formation, the template DNA was passed through a spin column with a nominal molecular weight cut off of $100 \mathrm{bp}$ (Chromaspin - 100 in DEPC $\mathrm{H}_{2} \mathrm{O}$; Clontech) as described by the manufacturer. This column allows the template DNA and annealed TFO to pass through into DEPC $\mathrm{H}_{2} \mathrm{O}$ while retaining $90 \%$ of excess oligonucleotide and $99 \%$ of the buffer ions. After purifying the template DNA from excess oligonucleotide, transcription reactants were added to achieve a final volume of $75 \mu \mathrm{l}$ with final concentrations as follows: $\mathrm{MgCl}_{2}=2 \mathrm{mM} ; \mathrm{KCl}=44 \mathrm{mM}$; Tris- $\mathrm{HCl}, \mathrm{pH} 7.4,8.8 \mathrm{mM}$; Hepes, pH 7.9, $4.4 \mathrm{mM}$; EDTA $=88 \mu \mathrm{M}$; DTT $=220 \mu \mathrm{M}$; glycerol $=8.8 \% \mathrm{vol} / \mathrm{vol} ; \mathrm{ATP}=400 \mu \mathrm{M} ; \mathrm{UTP}=400 \mu \mathrm{M} ; \mathrm{CTP}=400 \mu \mathrm{M} ; \mathrm{GTP}$ $=16 \mu \mathrm{M} ;{ }^{32} \mathrm{P}-\{\alpha\} \mathrm{GTP}$ at $3,000 \mathrm{Ci} / \mu \mathrm{mol}=30 \mu \mathrm{Ci}$ (total activity). Transcription was initiated by adding HeLa nuclear extract (Promega Biotec) $102 \mu \mathrm{g}$ and incubating at $30^{\circ} \mathrm{C}$ for $1 \mathrm{~h}$. Transcription was stopped by adding $4.5 \mathrm{vol}$ of a solution of $0.3 \mathrm{M}$ Tris- $\mathrm{HCl}$ ( $\mathrm{pH} 7.4), 0.3$ $M$ sodium acetate, $0.5 \%$ ( $\mathrm{vol} / \mathrm{vol}$ ) SDS, $2 \mathrm{mM}$ EDTA, $3 \mu \mathrm{g} / \mathrm{ml}$ transfer RNA. Reaction products were extracted once with phenol/chloroform/isoamyl alcohol (25:24:1) and ethanol precipitated. Transcripts were resuspended in $50 \%$ formamide, denatured at $95^{\circ} \mathrm{C}$, and separated on an $8 \mathrm{M}$ urea, $5 \%$ acrylamide gel. Bands were visualized by autoradiography and compared to a labeled, denatured $\phi$ X174/HaelII digested molecular weight marker.

\section{Results}

Triplex formation and its effects on protein binding to the HER-2/neu promoter were demonstrated by gel mobility shift and DNaseI protection assays. The triplex target site in the HER-2/neu promoter is a purine-rich sequence from -42 to -69 as illustrated in Fig. 1. The triplex-forming oligonucleotides include the antiparallel and linker substituted antiparallel sequences illustrated in Fig. 2. The parallel oligonucleotide (Fig. 2) was used as a control oligonucleotide that would not form triplex with the target sequence.

Gel mobility shift analysis using oligonucleotides reveals concentration dependent triplex formation by the antiparallel polypurine strand targeted to the HER-2/neu promoter sequence (Fig. 3). Gel shifts were performed by adding successively greater concentrations of the parallel or antiparallel purine-rich oligonucleotides to the triplex target sequence labeled on the pyrimidine-rich strand under the conditions described. The parallel purine-rich oligonucleotide is identical to the purine-rich strand of the target sequence in both sequence and orientation; the antiparallel oligonucleotide is identical in sequence, but reversed in orientation with respect to the purinerich strand of the target sequence (Fig. 2). Triplex formation occurs when the triplex-forming oligonucleotide is at 3.3 $\times 10^{-7} \mathrm{M}$ concentration (100-fold excess with respect to the duplex concentration), and the shift is complete at $3.3 \times 10^{-6}$ M (1,000-fold excess). This is consistent with a dissociation

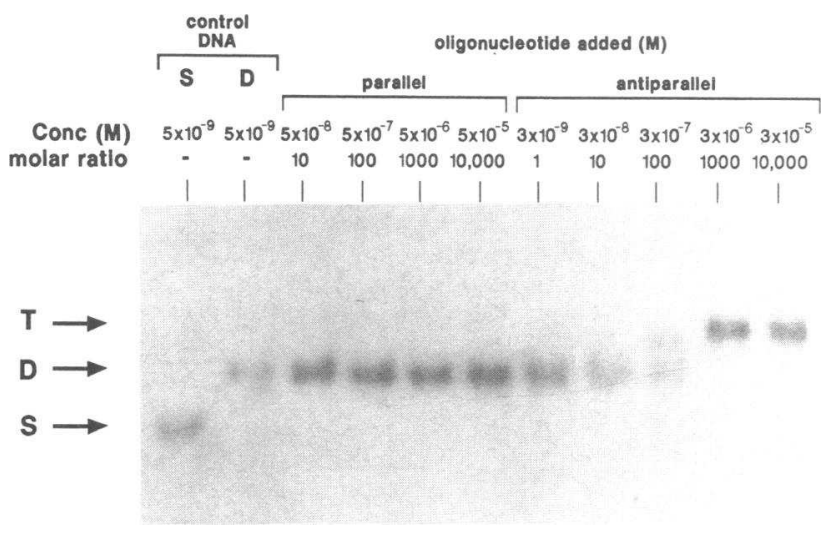

Figure 3. Gel mobility shift analysis showing concentration dependent triplex formation. In all lanes, the 28-base pyrimidine rich strand of the target sequence is labeled. The labeled strand was annealed to its purine-rich complement, and the parallel or antiparallel purine rich oligonucleotides were added as described in Methods. Single and double strand controls were included. The concentration of the target sequence was constant at $5 \times 10^{-9} \mathrm{M}$ for the control lane and parallel lanes and at $3.3 \times 10^{-9} \mathrm{M}$ (numbers in figure have been truncated for clarity) in the antiparallel lanes. The oligonucleotide added, its concentration, and its molar ratio to the target DNA are indicated. $S$, single strand DNA; $D$, duplex DNA; $T$, triplex DNA.

constant $\left(K_{\mathrm{d}}\right)$ of $4.5 \times 10^{-7} \mathrm{M}$. The antiparallel oligonucleotide was found to be triplex forming, but the parallel oligonucleotide failed to demonstrate triplex formation at concentrations up to $5 \times 10^{-5} \mathrm{M}$ (10,000-fold excess).

The sequence specificity of triplex formation was confirmed by DNase I protection footprinting (Fig. 4). A 267-bp fragment of the HER-2/neu promoter was labeled on either the coding or noncoding strand and incubated with increasing concentrations of the triplex-forming oligonucleotide before limited digestion by DNase I. Protection of the target sequence by the triplex-forming oligonucleotide was observed to be concentration dependent in a manner consistent with the gel mobility shift analysis. Protection from digestion is demonstrated at $10^{-6} \mathrm{M}$ concentration of the antiparallel oligonucleotide, the concentration at which the target duplex was completely shifted to DNA triplex in the gel shift experiments. The parallel polypurine oligonucleotide, however, did not protect the HER2 /neu promoter fragment from DNase I digestion at the same concentration.

The effect of triplex formation on protein binding to the HER-2/neu promoter was evaluated. Gel mobility shift analysis of a 120-bp restriction fragment of the HER-2/neu promoter incubated with a HeLa nuclear extract shows several shifted bands representing different protein-DNA complexes (Fig. 5). Protein binding was inhibited by preincubation of the HER-2/neu promoter fragment with the triplex-forming antiparallel oligonucleotide at a concentration of $5 \times 10^{-6} \mathrm{M}$ ( 1,000 -fold excess). Prevention of protein binding was shown to depend on the concentration of the triplex-forming oligonucleotide. The concentration of oligonucleotide that prevents protein binding is consistent with the concentration that induced complete triplex formation in the experiments described above. The parallel polypurine oligonucleotide did not prevent protein binding at this concentration.

Protein binding directly to the 28-bp target sequence was demonstrated in gel mobility shift analysis (Fig. 6). HeLa nu- 


\section{Coding Strand}
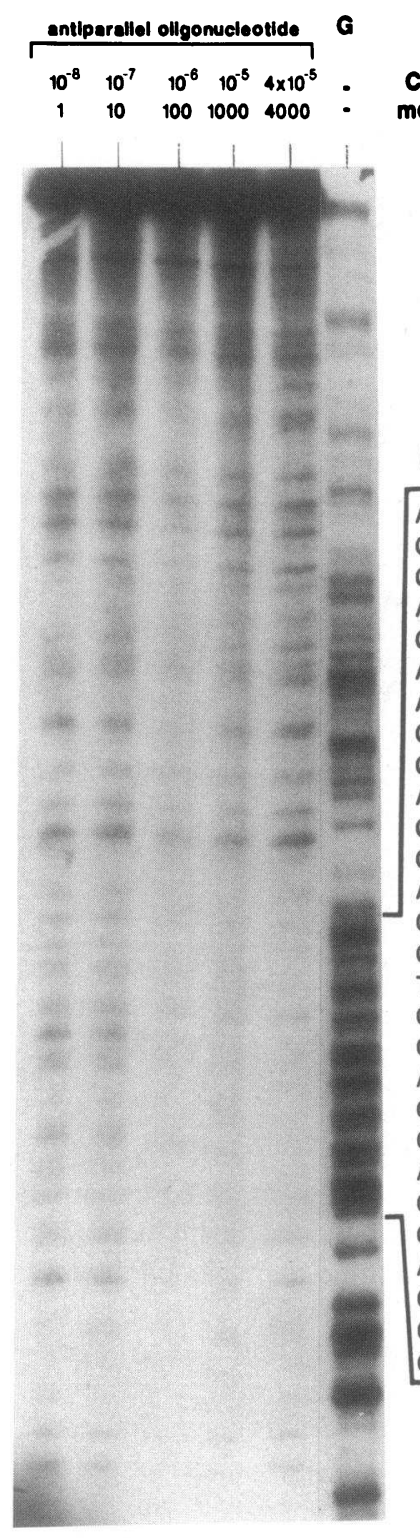

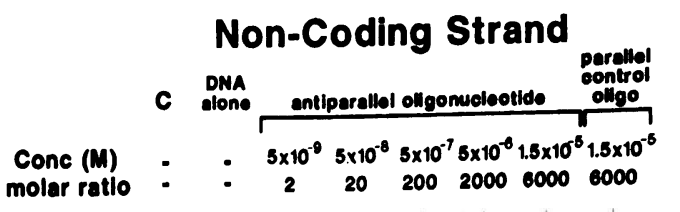

$(-69)$

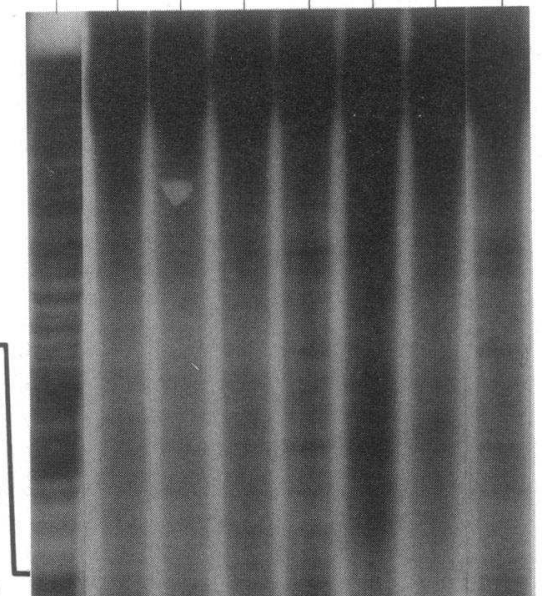

Figure 4. DNase I footprints of triplex formation by the antiparallel purine-rich oligonucleotide in the HER-2/neu promoter. 267-bp fragments of HER-2/ neu promoter were labeled and incubated with the oligonucleotides as described. Limited DNAse I digestion was performed, then the DNA was resolved on an $8 \%$ polyacrilamide sequencing gel $8 \mathrm{M}$ in urea followed by autoradiography. Maxam-Gilbert sequencing reaction were performed $(G$ and $C)$ and were run simultaneously for orientation; the target sequence is indicated. Concentration and molar ratio of the oligonucleotides with respect to the HER-2/ neu promoter fragment are indicated. The parallel purine-rich oligonucleotide was included as a control.

clear extract was added to a labeled synthetic double stranded 28-mer corresponding to the target sequence and a single dominant shift was observed. Preincubation of the target sequence with the triplex forming oligonucleotide but not the parallel polypurine strand $\left(2.5 \times 10^{-6} \mathrm{M}\right.$ in both cases $)$ prevented this shift.

The effects of triplex formation were examined in an in vitro "run off" transcription assay (Fig. 7). In this assay, a eukaryotic promoter is incubated with a HeLa nuclear extract in the presence of nucleotide triphosphates; transcripts are labeled by the incorporation of ${ }^{32} \mathrm{P}-\mathrm{GTP}$ and correspond in size to the length of the template DNA. A NotI digest of the plasmid containing the HER-2/neu promoter yields a 610-bp fragment with 368 bp downstream of the transcription start site (thus yielding a 368-base transcript). When this promoter fragment was incubated with the triplex forming oligonucleotide, a concentration dependent inhibition of HER-2/neu transcription was observed (Fig. $7 A$ ). Substantial inhibition of transcription was seen with oligonucleotide concentrations of $2.5 \mu \mathrm{M}$ and complete inhibition of transcription is seen when the oligonucleotide concentration is $25 \mu \mathrm{M}$. A purine-rich control (nontriplex-forming) oligonucleotide targetted to an adjacent potential triplex site in the HER-2/neu promoter had no effect on in vitro transcription at $25 \mu \mathrm{M}$. It has been shown that DHFR transcription in vitro is enhanced when the template DNA is a digested plasmid containing both the promoter and the plasmid backbone (30). We observed similar results with HER-2/ neu. Using digested plasmid DNA as the template, high molecular weight bands are observed at $\sim 600$ and 1,500 bases; presumably these bands represent interaction of the protein extract with the plasmid backbone and similar high molecular weight bands have been observed in DHFR transcription in vitro (30). In contrast, two lower molecular weight transcripts of $\sim 250$ and 150 bases represent premature termination of transcription. These lower molecular weight transcripts are also specifically inhibited by the triplex-forming oligonucleo- 


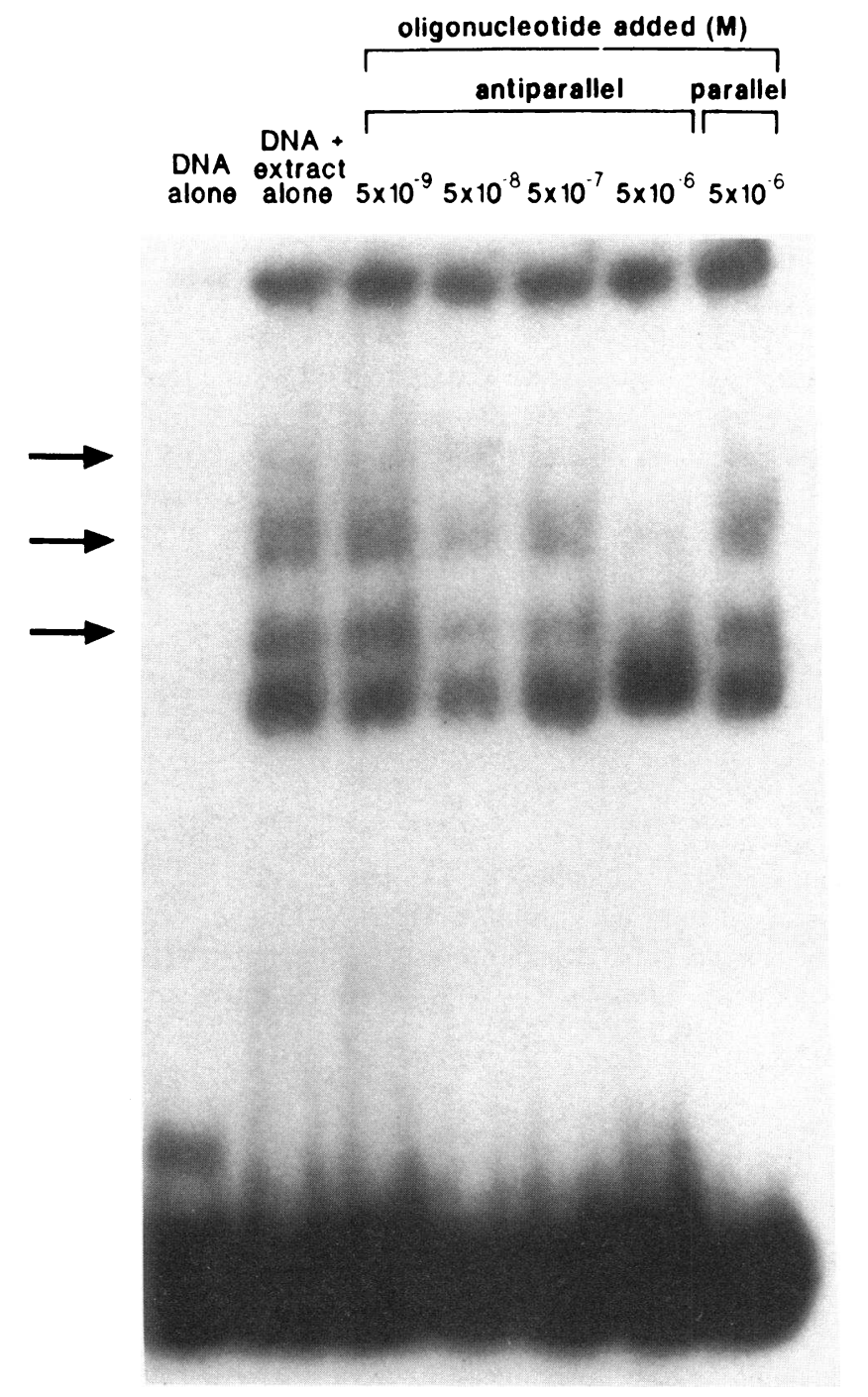

Figure 5. Gel mobility shift analysis demonstrating protein binding by a nuclear extract to the HER-2/neu promoter. A 119-bp fragment of the HER-2/ neu promoter was labeled and incubated with a HeLa nuclear extract as described. In the "oligonucleotide added" lanes, the DNA was preincubated with the antiparallel or parallel purinerich oligonucleotides at the concentrations indicated. Arrows indicate protein-DNA complexes that are prevented by the triplex formation.

tide in a concentration dependent manner. To further demonstrate the specificity of the oligonucleotide effect on transcription, the CMV promoter was used as a negative control (Fig. 7 $B)$. A 363-base transcript is synthesized from this CMV template in vitro, and neither the triplex-forming oligonucleotide nor the control oligonucleotide had an effect on CMV transcription in this assay system.

It should be mentioned that large excesses of several oligonucleotides (triplex-forming and non-triplex-forming) had a nonspecific inhibitory effect on the in vitro transcription of both the HER-2/neu and CMV genes (data not shown). This nonspecific effect was overcome by purifying the template DNA from excess oligonucleotide by molecular-sieve chromatography. Specifically, the template DNA was incubated with the oligonucleotide and then passed through a spin column with a nominal molecular weight cut off of $100 \mathrm{bp}(50 \mathrm{kD})$. Oligonucleotide bound to the template DNA passed through the column as a stable triplex, while $>90 \%$ of unbound oligonu- cleotide is retained in the column (data not shown). Template DNA purified in this way retains full promoter activity in the absence of triplex.

The triplex target sequence in the HER-2/neu promoter contains a single pyrimidine residue at -54 (Fig. 1). This thymidine residue is unable to Hoogsteen bond with the corresponding thymidine residue of the antiparallel triplex forming oligonucleotide, interrupting the R:R:Y triplex motif at this site. We sought to bridge this pyrimidine interruption with an abasic molecule that preserves internucleotide spacing, and compare the relative triplex forming ability of the substituted oligonucleotide with the unsubstituted oligonucleotide.

Triplex formation by the oligonucleotide with the abasic linker substitution was demonstrated by gel mobility shift analysis (Fig. 8). Again, a concentration dependent shift to triple helix formation was observed. The linker substituted oligonucleotide induces triplex formation at a concentration of $10^{-7}$ $\mathrm{M}$, with a complete shift to triplex at $10^{-6} \mathrm{M}$. This is consistent with a $K_{\mathrm{d}}$ of $\sim 5 \times 10^{-7} \mathrm{M}$. Therefore, the binding affinity of the linker substituted oligonucleotide was approximately equivalent to the affinity of the unsubstituted oligonucleotide.

\section{Discussion}

We have demonstrated the formation of an interstrand DNA triplex of the R:R:Y type by a polypurine oligonucleotide tar-

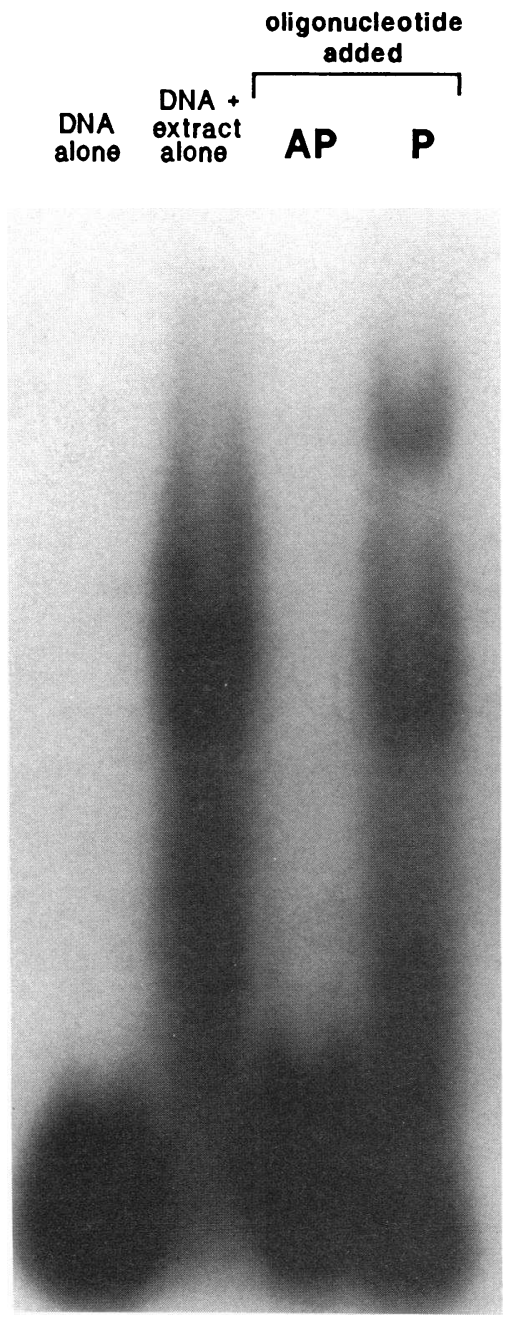

Figure 6. Gel mobility shift analysis of protein binding to the triplex target sequence by a HeLa nuclear extract. The pyrimidine-rich strand of the target sequence was synthesized, labeled, and annealed to its complement as described, then incubated with a HeLa nuclear extract. In the "oligonucleotide added" lanes, the DNA was preincubated with the antiparallel $(A P)$ or parallel $(P)$ oligonucleotides at concentrations of $2.5 \times 10^{-6} \mathrm{M}$ to show that triplex formation prevents protein binding to the target sequence. 


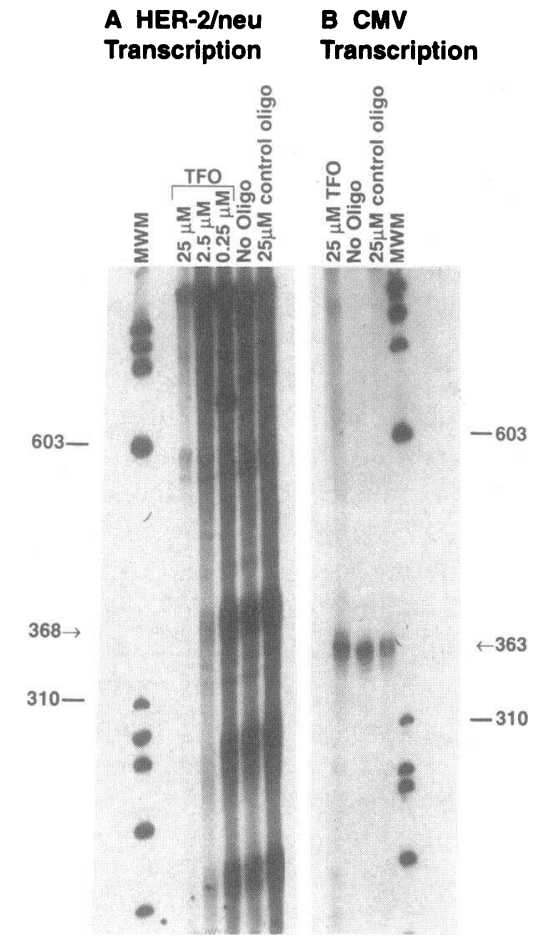

Figure 7. In vitro transcription assay demonstrating specific inhibition of HER-2/neu transcription. $(A)$ Transcription from a digested plasmid containing the HER-2/neu promoter-template. $(B)$ Transcription from a purified CMV promoter template. Oligonucleotides were added to the template DNA as described at the concentrations indicated above each lane. HER-2/neu transcription yields a full-length 368-base RNA transcript (arrow), as well as two smaller prematurely terminated transcripts of $\sim 250$ and 150 bases. These transcripts are inhibited by triplex formation with the anti-

parallel 28 base oligonucleotide in a concentration dependent fashion A purine-rich oligonucleotide antiparallel to an adjacent target site does not form triplex and has no effect on in vitro transcription (control oligo). Large molecular weight bands in $A$ at 600 and 1,500 bases represent interaction of the HeLa extract with the plasmid backbone and are not HER-2/neu transcripts. CMV transcription with a purified promoter template yields a single 363-base transcript (arrow, B). Neither the TFO nor the control oligonucleotide have an effect on CMV transcription. $M W M, \phi \mathrm{X} 174 / \mathrm{Ha}$ III molecular weight marker with the 310 and 603 base standards indicated.

getted to the HER-2/neu promoter. Triplex formation blocked protein binding to the target site and possibly to other sites as well. Triplex formation was dependent on the presence of magnesium ion, but occurred at physiologic $\mathrm{pH}$ with nanomolar concentrations of oligonucleotide. Triplex formation is a site specific phenomenon in which the oligonucleotide forms specific G:G:C and A:A:T triplets with the HER-2/neu promoter target sequence by Hoogsteen hydrogen bonding. Several recent reports suggest that triplex formation is possible under near physiologic conditions of $\mathrm{pH}$, temperature, and ion concentrations, and triplex forming oligonucleotides targetted to cellular genes may be expected to form triplex structures in the living cell $(14,22)$. Triplex formation in the c-myc promoter of cultured HeLa cells has recently been reported (22). In this setting, triplex-forming oligonucleotides may have potential application as agents that target a gene in a sequence specific manner and prevent gene expression by inhibiting transcription. Inhibition of in vitro and in vivo transcription of another biologically and clinically important oncogene, c-myc, has already been demonstrated with triplex formation $(14,22)$. We have shown the specific inhibition of HER-2/neu transcription in vitro through triplex formation.

The target sequence for triplex formation in the HER-2/ neu oncogene reported here is likely to be important for the regulation and efficient transcription of the HER-2/neu gene. We have shown that this sequence is a binding site for a nuclear protein. The identity of the protein and its significance are not known, but the sequence homology with the TC factor recognition site in the EGF-R promoter (13) suggest that it may be of importance in HER-2/neu expression. Inhibition of HER-2/ neu transcription by triplex formation may occur by blocking the binding of this protein, which may be a transcription factor necessary for efficient HER-2/neu expression. In addition, the triplex target site is flanked by two important and well-recognized transcription factor recognition sites, the CCAAT sequence (recognition site for the protein CTF) and the TATA box (recognition site for the essential transcription factor TFIID) (Fig. 1). Triplex formation in the target region may have an effect on the nearby binding of these two factors by changing the local DNA conformation of the flanking sequences, thereby preventing formation of the transcription initiation complex whereby RNA polymerase recognizes the transcription start site $(+1)$ to begin RNA synthesis (31). Finally, triplex formation may affect the DNA conformation at distal sites (31); triplex formation at the target site of HER-2/neu may therefore prevent RNA polymerase II itself from binding to the DNA template.

An important limitation to the application of triplex formation to naturally occurring DNA sequences is the requirement for polypurine:polypyrimidine tracts. Although these sequences occur in nature, naturally occurring polypurine tracts are frequently interrupted by one or several pyrimidines. These pyrimidine residues could disrupt triplex formation in an otherwise favorable triplex target site by loss of triplet hydrogen bonds and unfavorable steric interaction of the pyrimidines (26). We have examined an abasic linker molecule that could provide a bridge over the pyrimidine interruptions that often are found in naturally occurring purine-rich sequences. Recently, a neutral abasic linker was reported to substitute for a base in a polypyrimidine triplex forming oligonucleotide in a Y:R:Y triplex motif (32). We have shown that a positively charged linker substituted oligonucleotide retains the ability to form triplex with its target sequence in an $R: R: Y$ triplex. It is

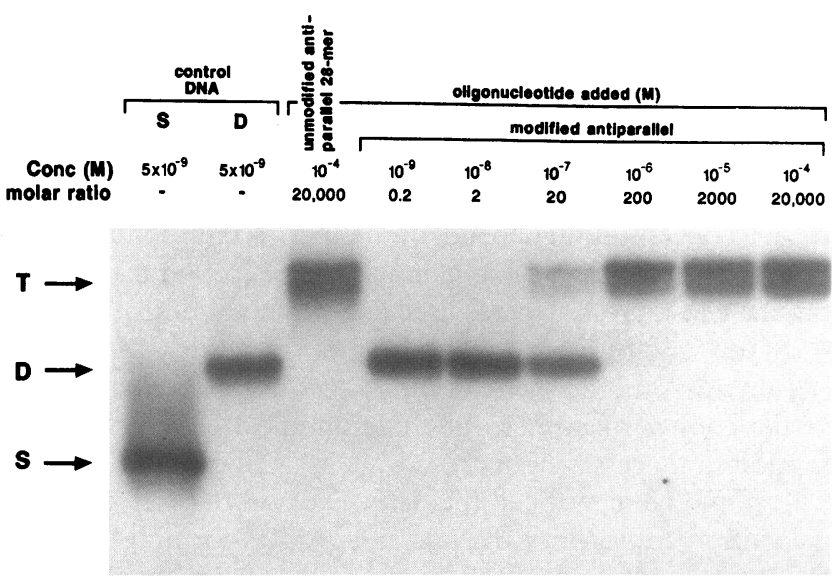

Figure 8. Gel mobility shift analysis demonstrating concentration dependent triplex formation by the linker substituted oligonucleotide. Conditions for the experiment were similar to those described for other gel shifts. Single and double stranded controls were included, and triplex formation with the unmodified oligonucleotide was included as a control. The concentration of oligonucleotide added as well as the molar ratio to the labeled DNA are indicated. $S$, single strand DNA; $D$, double strand DNA; $T$, triple strand DNA. 
not surprising that a single base substitution does not cause a substantial increase in affinity, since the loss or addition of a single hydrogen or salt bond would not have a large effect on the binding of this already stable triplex. Clearly, complete binding is observed in the substituted oligonucleotide and this linker molecule may be useful in targeting sequences with several interruptions in the polypurine motif that will not form triplex with other oligonucleotides. The positive charge on the amino group of this abasic linker may be responsible for its ability to retain equal binding affinity compared to the unsubstituted oligonucleotide. A previously reported abasic linker molecule is neutral and apparently confers a lower binding affinity on oligonucleotides in a Y:R:Y triplex (32).

The Hoogsteen bonding responsible for triplex formation can be expected to confer gene specificity on a triplex-forming oligonucleotide. The conditions of R:R:Y triplex formation suggest that it may be possible to target an oligonucleotide to the promoter of a living cell. Triplex formation may represent an important tool for modulation of gene expression in a gene specific manner. The data presented in this report suggest the potential future application of this tool in the specific modulation of HER-2/neu expression.

\section{Acknowledgments}

This work was supported by grants from the American Cancer Society (PRTF-153) (S. W. Ebbinghaus), Public Health Service (CA 0946708) (S. W. Ebbinghaus), National Institutes of Health (CA42664 and R01 CA 42337) (D. M. Miller), U. S. Army (DAMD 17-93-J-3018) (D. M. Miller), The Share Foundation (D. M. Miller), and a National Research Service Award (HL07457) (C. A. Mayfield).

\section{References}

1. Schubert, D., S. Heinemann, W. Carlisle, H. Tarikas, B. Kimes, J. Patrick, H. Steinbach, W. Culp, and B. L. Brandt. 1974. Clonal cell lines from the rat central nervous system. Nature (Lond.). 249:224-227.

2. Shih, C., L. C. Padhy, M. Murray, and R. A. Weinberg. 1981. Transforming genes of carcinomas and neuroblastomas introduced into mouse fibroblasts. $\mathrm{Na}$ ture (Lond.). 290:261-264.

3. Schechter, A. L., D. F. Stern, L. Vaidyanathan, S. J. Decker, J. A. Drebin M. I. Greene, R. A. Weinberg. 1984. The neu oncogene: an erb-B-related gene encoding a 185,000-M $\mathrm{M}_{\mathrm{r}}$ tumor antigen. Nature (Lond.). 312:513-516.

4. L. Coussens, T. L. Yang-Feng, Y. L. E. Chen, A. Gray, J. McGarth, P. H Seeburg, T. A. Libermann, J. Schlessinger, U. Francke, A. Levinson, and A Ullrich. 1985. Tyrosine kinase receptor with extensive homology to EGF receptor shares chromosomal location with neu oncogene. Science (Wash. DC) 230:1132-1139.

5. Bargmann, C. I., and R. A. Weinberg. 1988. Oncogenic activation of the neu-encoded receptor protein by point mutation and deletion. EMBO (Eur. Mol. Biol. Organ.) J. 7:2043-2052.

6. Hung, M-C., D. H. Yan, X. Zhao. 1989. Amplification of the proto-neu oncogene facilitates oncogenic activation by a single point mutation. Proc. Natl. Acad. Sci. USA. 86:2545-2548.

7. Bargmann, C. I., M. C. Hung, R. A. Weinberg. 1986. The neu oncogene encodes an epidermal growth factor receptor-related protein. Nature (Lond.) 319:226-230.

8. Peles, E., S. S. Bacus, R. A. Koski, H. S. Lu, D. Wen, S. G. Ogden, R. B. Levy, and Y. Yarden. 1992. Isolation of the neu/HER-2 stimulatory ligand: a 22 kd glycoprotein that induces differentiation of mammary tumor cells. Cell. 69:205-216.

9. Slamon, D. J., G. M. Clark, S. G. Wong, W. J. Levin, A. Ullrich, W. L McGuire. 1987. Human breast cancer: correlation of relapse and survival with amplification of the HER-2/neu oncogene. Science (Wash. DC). 25:177-182.
10. Slamon, D. J., W. Godolphin, L. A. Jones, J. A. Holt, S. G. Wong, D. E. Keith, W. J. Levin, S. G. Stuart, J. Udove, A. Ullrich, and M. F. Press. 1989. Studies of the HER-2/neu proto-oncogene in human breast and ovarian cancer. Science (Wash. DC). 244:707-712.

11. Lemoine, N. R., S. Staddon, C. Dickson, D. M. Barnes, and W. J. Gullick 1990. Absence of activating transmembrane mutations in the c-erbB-2 proto-oncogene. Oncogene. 5:237-239, 1990.

12. Ishii, S., F. Imamoto, Y. Yamanashi, K. Toyoshima, and T. Yamamoto. 1987. Characterization of the promoter region of the human c-erbB-2 proto-oncogene. Proc. Natl. Acad. Sci. USA. 84:4374-4378.

13. Johnson, A. C., Y. Jinno, and G. T. Merlino. 1988. Modulation of epidermal growth factor receptor proto-oncogene transcription by a promoter site sensitive to S1 nuclease. Mol. Cell. Biol. 8:4174-4184.

14. Cooney, M., G. Czernuszewicz, E. H. Postel, S. J. Flint, and M. E. Hogan 1988. Site-specific oligonucleotide binding represses transcription of the human c-myc gene in vitro. Science (Wash. DC). 241:456-459.

15. Durland, R. H., D. J. Kessler, S. Gunnell, M. Duvis, B. M. Pettitt, and M. E. Hogan. 1991. Binding of triple helix forming oligonucleotides to sites in gene promoters. Biochemistry. 30:9246-9255.

16. Blume, S. W., J. E. Gee, K. Shrestha, and D. M. Miller. 1992. Triple helix formation by purine-rich oligonucleotides targeted to the human dihydrofolate reductase promoter. Nucleic Acids Res. 20:1777-1784.

17. Gee, J. E., S. Blume, R. C. Snyder, R. Ray, and D. M. Miller. 1992. Triplex formation prevents $\mathrm{Spl}$ binding to the dihydrofolate reductase promoter. J. Biol. Chem. 267:11, 163-11, 167 .

18. Grigoriev, M., D. Praseuth, P. Robin, A. Hemar, T. Saison-Behmoaras, A Dautry-Varsat, N. Thuong, C. Helene, and A. Harel-Bellan. 1992. A triplex-helix-forming oligonucleotide-intercalator conjugate acts as a transcriptional repressor via inhibition of NF KB binding to interleukin-2 receptor $\alpha$-regulatory sequence. J. Biol. Chem. 267:3389-3395.

19. McShan, W. M., R. D. Rossen, A. H. Laughter, J. Trial, D. J. Kessler, J. G. Zendegui, M. E. Hogan, and F. M. Orson. 1992. Inhibition of Transcription of HIV-1 in Infected Human Cells by Oligodeoxynucleotides Designed to Form DNA Triple Helices. J. Biol. Chem. 267:5712-5721.

20. Giovannangeli, C., M. Rougee, T. Garestier, N. Thuong, and C. Helene. 1992. Triple-helix formation by oligonucleotides containing the three bases thymine, cytosine, and guanine. Proc. Natl. Acad. Sci. USA. 89:8631-8635.

21. Maher, L. J., III, B. Wold, and P. B. Dervan. 1989. Inhibition of DNA binding proteins by oligonucleotide-directed triple helix formation. Science (Wash. DC). 245:725-730.

22. Postel, E. H., S. J. Flint, D. J. Kessler, M. E. Hogan. 1991. Evidence that a triplex forming oligodeooxyribonucleotide binds to the c-myc promoter in HeLa cells, thereby reducing c-myc mRNA levels. Proc. Natl. Acad. Sci. USA 88:822731.

23. Wells, R. D., D. A. Collier, J. C. Hanvey, M. Shimizu, and F. Wohlrab. 1988. The chemistry and biology of unusual DNA structures adopted by oligopurine oligopyrimidine sequences. FASEB (Fed. Am. Soc. Exp. Biol.) J. 2:29392949.

24. Letai, A. G., M. A. Palladino, E. Fromm, V. Rizzo, and J. R. Fresco. 1988. Specificity in formation of triple-stranded nucleic acid helical complexes: studies with agarose-linked polyribonucleotide affinity columns. Biochemistry. 27:91089112.

25. Beal, P. A., and P. B. Dervan. 1991. Second structural motif for recognition of DNA by oligonucleotide-directed triple-helix formation. Science (Wash DC). 251:1360-1363.

26. Mergny, J. L., J. S. Sun, M. Rougee, T. Montenay-Garestier, F. Barcelo, J. Chomilier, and C. Helene. 1991. Sequence specificity in triple-helix formation experimental and theoretical studies of the effect of mismatches on triplex stability. Biochemistry. 30:9791-9798.

27. Nelson, P. S., R. Sherman-Gold, and R. Leon. 1989. A new and versatile reagent for incorporating multiple aliphatic amines into synthetic oligonucleotides. Nucleic Acids Res. 17:7179-7186.

28. Dignam, J. D. Preparation of extracts from higher eurkaryotes. 1990. Methods Enzymol. 182:194-203.

29. Maxam, A. and W. Gilbert. 1980. Sequencing end-labeled DNA with base-specific chemical cleavages. Methods Enzymol. 65:499-560.

30. Farnham, P. J., and R. T. Schimke. 1986. In vitro transcription and delimitation of promoter elements of the murine dihydrofolate reductase gene. Mol. Cell. Biol. 6:2392-2401.

31. Maher III, L. J., P. B. Dervan, and B. Wold. 1992. Analysis of promoterspecific repression by triple-helical DNA complexes in a eukaryotic cell-free transcription system. Biochemistry. 31:70-81.

32. Horne, D. A. and P. B. Dervan. 1991. Effects of an abasic site on triple helix formation characterized by affinity cleaving. Nucleic Acids Res. 19:49634965 . 